\title{
Proposta de Questionário de Histórico de Linguagem e Autoavaliação de Proficiência para Professores Ouvintes Bilíngues $\mathcal{L}$ ibras/Língua Portuguesa
}

\author{
Proposing a Language Experience and Self-Assessment of \\ Proficiency Questionnaire for Bilingual Brazilian Sign \\ Language/Portuguese Hearing Teachers
}

\section{Ingrid FINGER * Vinicius Martins FLORES **}

Resumo: O presente artigo apresenta uma proposta de questionário de avaliação da experiência linguística e de autoavaliação de proficiência para professores ouvintes que utilizam a Libras e o Português Brasileiro em sua atuação na educação de surdos. Nosso objetivo é apresentar uma ferramenta que possa complementar as informações obtidas através de uma medida independente de proficiência nas línguas ou até mesmo substituí-la, contemplando as especificidades do uso, atitudes e proficiência da Libras em contexto de uso no exercício da docência em espaço educacional formal. Do ponto de vista da fundamentação teórica, justifica-se o questionário considerando fatores importantes nos estudos de bilinguismo onde é necessário conhecer e reconhecer o contexto familiar, profissional e social do sujeito da pesquisa (KAUFMANN, 2010). O questionário proposto tem como modelo o LEAP-Q (MARIAN; BLUMENFELD; KAUSHANSKAYA,

\footnotetext{
* Mestrado (1995) e Doutorado (2000) em Linguística e Letras, PUCRS. Pós-Doutorado na Georgetown University (2011). Universidade Federal do Rio Grande do Sul e CNPq. Contato: finger.ingrid@gmail.com.

** Mestrado em andamento em Letras - Linguística Aplicada, UFRGS. Universidade Estadual do Rio Grande do Sul e Universidade Luterana do Brasil. Contato: viniciusmartinsf@gmail.com.
} 
2007), o SLSCO - Sign Language Skills Classroom Observation (REEVES et al., 2000) e o Questionário de Atitudes Linguísticas (KAUFMANN, 2010), levando também em consideração os diversos tipos de exposição à Libras bem como suas diferentes realidades de uso no contexto brasileiro. O contexto para aplicação é de professores ouvintes bilíngues bimodais, que atuam em escolas bilíngues para Surdos e/ou que atuam com Atendimento Educacional Especializado direcionado a alunos surdos.

Palavras-chave: Questionário de Histórico da Linguagem. Autoavaliação da proficiência em Libras. Professores ouvintes bilíngues bimodais.

\begin{abstract}
This article presents a language experience and self-assessment of proficiency questionnaire for hearing teachers who use Brazilian Sign Language and Portuguese in their teaching practice. By focusing on hearing teachers who work in Deaf education contexts, this questionnaire is presented as a tool that may complement the assessment of linguistic skills of hearing teachers. This proposal takes into account important factors in bilingualism studies such as the importance of knowing the participant's context with respect to family, professional and social background (KAUFMANN, 2010). This work uses as model the following questionnaires: LEAP-Q (MARIAN; BLUMENFELD; KAUSHANSKAYA, 2007), SLSCO - Sign Language Skills Classroom Observation (REEVES et al., 2000) and the Language Attitude Questionnaire (KAUFMANN, 2010), taking into consideration the different kinds of exposure to Brazilian Sign Language. The questionnaire is designed for bilingual bimodal hearing teachers who work in bilingual schools for the Deaf or who work in the specialized educational department who assist deaf students.
\end{abstract}

Keywords: Language History Questionnaire. Self-assessment of Brazilian Sign Language proficiency. Bimodal bilingual hearing teachers

\title{
Introdução
}

No cenário das políticas linguísticas mundiais, é cada vez mais privilegiado o direito de o indivíduo surdo possuir acesso educacional em sua primeira língua, uma língua de sinais, direito esse garantido pela Declaração Universal dos Direitos Linguísticos (OLIVEIRA, 2003). No Brasil, a legislação prevê o atendimento da população surda no âmbito escolar e não escolar, a 
partir das exigências criadas pelo Decreto n ${ }^{\circ}$ 5.626/05 (BRASIL, 2005), que regulamenta a Lei $\mathrm{n}^{\circ} 10.436 / 2002$ (BRASIL, 2002), que trata do acesso de alunos surdos à escola e dispõe sobre a inclusão da Libras (Língua Brasileira de Sinais) como disciplina curricular, a formação e a certificação de intérprete de Libras, o ensino da Língua Portuguesa como segunda língua para alunos surdos e a organização da educação bilíngue no ensino regular. Além disso, a Política Nacional de Educação Especial foi elaborada a partir de uma perspectiva da educação inclusiva de acordo com a portaria no 555/2007 e 948/2007 (BRASIL, 2008) e define que a educação especial é uma modalidade de ensino que perpassa todos os níveis, etapas e modalidades e deve se dar por meio do Atendimento Educacional Especializado (doravante, AEE) ${ }^{1}$. A legislação e os materiais didáticos disponibilizados pelo Ministério da Educação e Cultura, entretanto, ainda carecem de definições a respeito do tipo de formação linguística mínima que um professor ouvinte bilíngue Libras/Português Brasileiro, que exerça docência em escolas bilíngues para surdos, ou em escolas de inclusão que atendam usuários de Libras e realizam o AEE nas suas diferentes formas, sendo ensino de Libras, em Libras e o ensino de Língua Portuguesa.

Percebe-se que é necessário propor um novo olhar para o espaço bilíngue da educação de surdos, que vem ao encontro não somente dos educandos surdos, mas sim dos docentes ouvintes que são maioria nesse processo de ensino-aprendizagem, e que empregam a Libras como língua de instrução e comunicação com seus discentes surdos. A realidade atual é de que o professor ouvinte exerce um papel essencial nesse processo devido principalmente ao fato de a escola de surdos/escola inclusiva possui um número superior de professores ouvintes, em comparação com professores surdos. Assim, o aluno surdo, a maioria sendo filhos de pais ouvintes que desconhecem Libras, chega na escola com uma experiência de linguagem única, e muitas vezes com atraso escolar. E o professor ouvinte será o único elo nesse processo de ensino-aprendizagem que buscará suprir as demandas e necessidades desses alunos surdos que têm muitas vezes como única fonte de informação o que o docente apresenta no espaço de educação formal.

${ }^{1}$ O Decreto n $^{\circ}$ 6.094/2007 estabelece, dentre as diretrizes do Compromisso Todos pela Educação, a garantia do acesso e permanência no ensino regular, incluindo a formação de professores e a garantia de atendimento para que não haja evasão escolar. 
É nesse contexto que se insere o presente artigo, que tem como objetivo apresentar um questionário de histórico de linguagem e de autoavaliação de proficiência de professores ouvintes bilíngues bimodais que possuam o par linguístico de atuação Libras e Português Brasileiro. Nosso propósito foi elaborar um instrumento que possa verificar a experiência linguística bem como avaliar o grau de bilinguismo de docentes ouvintes, considerando o espaço onde a Libras é a primeira língua de ensino, e o Português Brasileiro na modalidade escrita é a segunda língua.

\section{A Escola Bilíngue de Surdos e a Formação Linguística do Professor Ouvinte}

$\mathrm{Na}$ escola bilíngue para surdos ou no AEE há muitos professores considerados bilíngues. Mas como acontece o bilinguismo na docência? Qual a formação que melhor contempla e proporciona um uso de Libras de forma clara e compreensível para o processo de ensino-aprendizagem? O que caracteriza um professor bilíngue? Qual a sinalização adequada para transmitir conhecimentos escritos em português nos livros didáticos que são utilizados no ensino de alunos surdos usuários de Libras? As respostas para essas perguntas são complexas e não teríamos como responder sem antes começar a investigar a proficiência linguística dos docentes responsáveis pela educação de surdos no espaço da educação especial e educação inclusiva. Propor um questionário de histórico de linguagem e de autoavaliação de proficiência possibilita que tenhamos um panorama de fatores comuns entre os docentes, para mapear as formações, localizar aspectos culturais e linguísticos, compreender as necessidades de formação específica e para assim nos possibilitar qualidade de interação comunicacional entre discentes surdos e docentes bilíngues.

É importante ressaltar que o embate sobre escolas bilíngues ou escolas de inclusão não será abordado de forma exaustiva, pois nosso propósito é avaliar a formação linguística dos professores ouvintes bimodais que atuam com duas línguas (Libras/Língua Portuguesa) na formação de sujeitos surdos participantes de nossa sociedade brasileira. Além disso, como enfatiza Santos (2012, p. 78), "o sucesso escolar do aluno não é definido a partir do tipo de oferta educativa.” Nessa discussão, o autor defende que 
A escola especial para o surdo não se sustenta a partir dos argumentos de que 'seu contrário' - a escola regular - fracassou diante do aluno surdo. E a escola regular não garante seu espaço diante do discurso de inclusão. Assim, ambas se afastam da discussão do processo educativo dos seus alunos, do currículo, do trabalho coletivo da escola e dos objetivos educacionais. (SANTOS, 2012, p. 78)

As discussões necessitam avançar além dos espaços físicos, das nomeações das escolas, e assim adentrar um campo de práticas bilíngues onde os sujeitos possam interagir e comunicar-se em Libras sem barreiras e limitações. Os docentes carecem de um suporte para o aprendizado de Libras, os discentes almejam um espaço bilíngue, e as políticas de formação não levam em consideração as necessidades escolares de capacitar novos professores bilíngues para o ensino de surdos. A necessidade de domínio de uso de Libras por parte dos professores no contexto escolar é inquestionável se considerarmos que

... a utilização de uma mesma língua entre sujeitos é essencial, pois é por meio dela que o sujeito apropria-se dos conhecimentos que são conduzidos ao plano intrapessoal (operação interna), para, assim, orientar e controlar seu próprio comportamento. Ao internalizar os conhecimentos que foram significados pelo outro, produz em si uma reconstrução interna de uma operação externa (interpessoal) propiciada pela linguagem. (FERREIRA; ZAMPIERI, 2009, p. 99).

O docente bilíngue Libras-Português Brasileiro possui um papel fundamental ao intermediar a construção de conhecimentos e expressão de ideias do discente surdo no espaço escolar. Sua formação, entretanto, é ainda bastante deficitária no Brasil. Os cursos de Licenciatura oferecem apenas uma disciplina obrigatória de Libras, seguindo o Decreto $\mathrm{n}^{\circ} 5.626$, de 22 de dezembro de 2005, e a legislação vigente não especifica as habilidades que devem ser estimuladas nem o nível de proficiência mínimo que deve ser exigido dos professores em formação. Sabe-se que as universidades estão realizando uma leitura semelhante da legislação e estipulado uma disciplina de quatro créditos (em média de 60 a 72 horas/aula) de Libras que, a nosso ver, representa uma carga horária muito aquém do necessário para que o professor em formação adquira conhecimento sobre Libras e a educação de surdos. 
Essa carga horária dificilmente proporciona oportunidade para que um professor se torne proficiente em Libras e capacitado para ministrar conteúdos escolares tendo Libras como língua de instrução.

Alguns autores (LODI; MÉLO; FERNANDES, 2012, dentre outros) enfatizam que é muito recente o uso de Libras como língua de instrução de alunos surdos, bem como a concepção de que a Libras deve ser mantida como a primeira língua para alunos surdos e segunda língua para professores ouvintes. Por isso, é comum constatarmos que o único critério utilizado para decidir sobre a contratação de professores que atuem nas escolas de surdos / de inclusão é ser um adulto surdo, a fim de que ele possa se tornar uma referência linguística para os discentes surdos. Assim, o adulto surdo, que inúmeras vezes não possui formação como professor, passa a ser o responsável pela língua de sinais dentro do espaço educacional. Essa constatação é discutida no excerto abaixo.

Nos últimos cinco anos, a língua brasileira de sinais vem recebendo cada vez mais atenção por parte de pesquisadores e educadores, bem como é crescente o número de adeptos e defensores do seu uso. As escolas que atendem alunos surdos estão contratando adultos surdos para responder pela exposição dos alunos à língua de sinais, e as escolas regulares, em seus diferentes níveis, começam a contratar intérpretes, buscando obter resultados mais eficientes na relação professores ouvintes - alunos surdos. (PEREIRA, 2012, p. 236)

Outro aspecto interessante nesse contexto é que a mediação do conhecimento deve ser realizada essencialmente pelo docente. Incluir um intérprete de Libras no processo, repassando a ele o papel de único elo entre o professor ouvinte e o aluno surdo no espaço escolar, certamente acarreta consequências no nível de sucesso dos alunos. Sem dúvida, necessitamos de professores capazes de se comunicar de forma plena com seus discentes surdos. E novamente surge a dúvida sobre a formação. Já que o espaço é inclusivo, como utilizar duas línguas de modalidades distintas? Uma primeira opção é de que o professor ouvinte pode fazer uso do intérprete de Libras. Entretanto, no momento da interação direta com o aluno surdo o ideal é que essa ocorra em Libras, sem intermediário, dessa forma criando um elo comunicativo, proporcionando interação nas relações, construindo aprendizagens. 
A formação docente bilíngue ainda deve levar em consideração um contexto maior, onde os futuros discentes são também ouvintes, que por sua vez terão como professores indivíduos ouvintes de mesma cultura ou de pelo menos mesma língua.

É evidente que nossa cultura ouvinte está habituada a supor que o processo de entrada de regras gramaticais de uma língua para o indivíduo se dá através da exposição ao mundo da modalidade oral desta língua. Embora este seja o processo natural para o mundo dos ouvintes, isto não quer dizer, obrigatoriamente, que deve ser o processo natural para o mundo dos surdos. (SKLIAR, 2009, p. 96)

Segundo Lodi e Lacerda (2009, p. 100), “atribuir à linguagem função meramente comunicativa também ocorre nas salas de aula, em consonância com a formação tradicional de professores". Portanto, diferentes autores demonstram essa preocupação com a formação dos professores ouvintes na educação de surdos.

Muitas vezes, portanto, torna-se difícil para um ouvinte aceitar que os mecanismos mentais que levam à estruturação do domínio da língua encontram outras bases para desenvolver-se que não estão pautadas na exposição sonora. Negar esta premissa é negar uma evidência científica. Afirmar, no entanto, que este é o único caminho, é anticientífico, do mesmo modo, pois os pressupostos que regem o domínio da gramática de uma língua oral-auditiva não são apenas estes, mesmo para os ouvintes. Outro engano é supor que domínio de língua está automaticamente ligado à escrita e à oralização. Dominar a língua é dominar regras gramaticais, e os mecanismos cerebrais responsáveis por esse processo não estão escravizados à leitura ou à escrita e tampouco ao ouvir ou falar concretamente. (SKLIAR, 2009, p. 96-97).

Defendemos a necessidade de refletir sobre a formação docente no caso de professores ouvintes que atuam em escolas de inclusão ou de surdos, principalmente dado o fato de o ensino formal acontecer essencialmente na língua dominante do país, o Português, e devido ao fato de o Brasil não possuir uma tradição de escolas ou currículos bilíngues em geral, e menos 
ainda no caso de crianças surdas. Nessa perspectiva, a Libras aparece sendo uma forte aliada como ferramenta de ensino, sendo um grande diferencial para o ensino e principalmente uma forma de contemplar e diferenciar o ensino bilíngue no caso de alunos surdos.

\section{Elaboração do Questionário}

Com o objetivo de construir uma ferramenta que possa complementar as informações obtidas por meio de uma medida independente de proficiência nas línguas ou até mesmo substituí-la, o QueHLAP (Questionário de Histórico da Linguagem e Autoavaliação de Proficiência) teve como modelo o LEAPQ (MARIAN; BLUMENFELD; KAUSHANSKAYA, 2007), o SLSCO Sign Language Skills Classroom Observation (REEVES et al., 2000) e o Questionário de Atitudes Linguísticas (KAUFMANN, 2010). Tanto o LEAP-Q como o SLSCO e o Questionário de Atitudes Linguísticas se propõem (Esta preposição é necessária?) avaliar proficiência em línguas de modalidade oralauditiva, tendo como enfoque a investigação do uso, atitudes e proficiência das línguas envolvidas, mas não contemplando o bimodalismo, o percurso de formação formal linguística e aspectos gramaticais específicos da Libras. Dessa forma, defendemos a necessidade de buscar a construção de um novo instrumento para contemplar especificidades do uso, atitudes e proficiência da Libras em contexto de uso no exercício da docência em espaço educacional formal.

O QueHLAP foi dimensionado para ser usado com um grupo alvo que são os professores ouvintes usuários de Libras/Português Brasileiro, reconhecendo os contextos familiares, profissionais e sociais dos sujeitos de pesquisa a partir de questões que avaliam desde idade inicial de exposição, frequência e domínio de uso da Libras, além de aspectos culturais e linguísticos. Conforme Machado (2010), o conceito de proficiência pode ser em âmbito geral (global) da língua avaliada, ou nas habilidades de leitura, escrita, produção e compreensão. Nessa linha, o QueHLAP busca contemplar as diversas áreas de maneira global, mas enfocando na produção e compreensão da Libras, pelo fato de a escrita de sinais (leitura e escrita) ainda não ser utilizada na maioria das escolas de surdos nem em escolas inclusivas.

O QueHLAP para professores ouvintes bilíngues bimodais (Apêndice A) parte de uma pesquisa de estudos de relações de variáveis com observação direta intensiva, com uma entrevista padronizada, e inclui perguntas diretas 
que instigam respostas fechadas e abertas (MARCONI; LAKATOS, 2010). São consideradas sete áreas nos grupos de perguntas a fim de ampliar a eficácia e validade do questionário, a saber: (a) Identificação Pessoal; (b) Características Familiares; (c) Formação Acadêmica; (d) Formação Linguística; (e) Proficiência; (f) Uso e Interação entre/de Línguas; e (g) Metalinguagem.

As áreas de investigação do QueHLAP são constituídas conforme as características normalmente apresentadas em estudos envolvendo participantes bilíngues e/ou em estudos surdos. Na primeira área, de Identificação pessoal (questões 1 a 4), são apresentadas questões de identificação dos participantes, tais como: nome, idade, sexo, local de nascimento e nacionalidade. Essas informações visam auxiliar na identificação do participante caso sejam empregados outros testes no estudo.

A segunda área, de Características Familiares (questão 5), identifica o entrevistado como sendo ou não familiar de surdo, e, em caso afirmativo, qual é o nível de parentesco e se o indivíduo é usuário ou não de Libras em seu cotidiano. Essas informações visam a identificar e mensurar a quantidade e qualidade da exposição à Libras em contexto não formal a que o entrevistado tem ou teve acesso e por quanto tempo. Essas questões foram incluídas porque defendemos que os contextos de interação nos quais o indivíduo participa afeta de forma significativa o nível de proficiência adquirido como também a familiaridade e o conforto que o indivíduo possui para interagir na língua alvo. Além disso, Chin e Wiggelsworth (2007) chamam a atenção para a importância de levarmos em consideração o contexto de aquisição de todas as línguas do indivíduo em uma definição apropriada de bilinguismo.

As questões de número 6 a 12 pertencem à área de Formação Acadêmica, na qual se busca identificar informações sobre a trajetória de formação formal do professor ouvinte e quais os caminhos percorridos nessa formação profissional. Tais questões indagam sobre a possibilidade de o professor ouvinte bilíngue ter estado na posição de aprendiz num processo de formação acadêmica que, no geral, é realizada através da universidade ou centros de ensino. A investigação busca compreender que caminhos são percorridos por um docente para compor a formação acadêmica até ocupar o lugar de professor numa escola bilíngue.

$\mathrm{Na}$ área de Formação Linguística, as questões de 13 a 16 investigam o aprendizado da Libras, buscando identificar como o sujeito adquiriu ou está adquirindo a língua de sinais e em qual contexto esse processo aconteceu ou acontece. Essas questões visam buscar mais informações sobre a trajetória de 
aquisição da Libras, complementando os dados obtidos na questão 5 acima. Através dessas questões, o pesquisador poderá conhecer de forma detalhada os processos formais e informais de aprendizagem da Libras.

Nas questões 17 a 21, na área de Proficiência, o participante é solicitado a autoavaliar, em uma escala de -2 a +2 , qual o nível de proficiência que considera ter em Libras, em Português Brasileiro e outras línguas, em diferentes contextos. A escala utilizada nas questões 20 e 21 corresponde a seguinte representação: -2 (menos dois) a nenhum conhecimento, 0 (Zero) para uma comunicação mediana, 2 (dois) para uma excelente comunicação, e nos casos de -1 (menos um) e 1 (um) são os níveis intermediários entre um nível e outro. Aqui, chamamos a atenção para o fato de que, normalmente, refletir sobre a proficiência em uma língua de sinais significa considerar apenas a compreensão e a produção da sinalização, não abrangendo a leitura e escrita da Libras que, apesar de incipiente, existe em algumas escolas de surdos em nosso país. A nosso ver, é preciso considerar a existência da escrita de sinais e as consequências que aprender a escrita de sinais pode vir a ter na fluência do uso de Libras no caso de bilíngues ouvintes.

Para Fishman (1972), as experiências bilíngues são determinadas pelo uso que se faz das línguas. Buscando conhecer essas experiências bilíngues, a área de Uso e Interação entre/de Línguas, apresenta as questões de número 21 a 31, considerando os espaços de interação, as horas e modos de uso, a frequência de uso, sentimentos, preferências de uso da Libras ou do Português Brasileiro como língua de instrução e qual língua fica evidente nos processos de ensino e/ou social escolar. Nosso propósito aqui é analisar as experiências sociais e culturais do sujeito e onde e de que modo as línguas são empregadas. Conforme Grosjean (2013), os bilíngues adquirem e/ou usam as suas línguas com diferentes fins, em diferentes contextos, com diferentes usuários da língua. Caso o usuário tenha diversos domínios de uso da língua, maior o uso e maior a fluência, sendo os domínios de uso um fator que pode determinar a proficiência da língua.

Finalmente, na área denominada Metalinguagem (questão 33), novamente é utilizado o mesmo padrão de escala das questões 20 e 21, mas dessa vez com vistas a investigar o conhecimento do participante da gramática da Libras, questionando-se se os professores ouvintes sabem ou não nomear aspectos gramaticais utilizados em uma sinalização/interação em Libras. Chamamos a atenção para o fato de que a formação em Libras ocorre normalmente em Cursos de Libras em nível de extensão universitária ou em 
nível de disciplina de Libras em Cursos de Graduação, ou ainda em Cursos de Pós-graduação lato sensu em Libras (nível de Especialização), que habilitam professores ouvintes a serem profissionais bilíngues. A área do questionário que envolve questões sobre Metalinguagem propõe um espaço para verificar qual o conhecimento que os professores ouvintes bilíngues possuem de sua segunda língua, de como são percebidas as estruturas gramaticais. Aqui, é possível comparar os resultados obtidos pelos participantes no Questionário com uma testagem linguística a fim de verificar em que medida o usuário de Libras sabe nomear características gramaticais em sua sinalização.

Com essa diversidade de áreas de investigação, acreditamos que o QueHLAP pode vir a ser uma importante ferramenta que auxilie na formação de professores ouvintes bilíngues bimodais. Chamamos a atenção para a necessidade de se levar em consideração o uso da Libras em diferentes espaços e contextos tanto em cursos de formação de professores ouvintes bem como em processos em que é avaliada a proficiência desse professor. A padronização de um questionário de histórico de linguagem e proficiência para professores ouvintes bilíngues ajudará no entendimento dos resultados das pesquisas sobre bilinguismo dos docentes e poderá contribuir no sentido de investigar os diferentes tipos de bilíngues bimodais que circulam nos espaços educacionais.

\section{QueHLAP e os Instrumentos de Avaliação}

O QueHLAP, em sua elaboração, contemplou os estudos anteriores em diferentes áreas do conhecimento, para dessa forma considerar uma gama de informações durante a aplicação da autoavaliação de proficiência, que pode ser usada em conjunto com um instrumento de avaliação linguística. Os estudos referentes ao bilinguismo bimodal, que nesse caso se refere a pessoas ouvintes usuárias de Libras e Português Brasileiro, é inicial quando comparado com outros pares de línguas cujas modalidades são diferentes.

Nos estudos sobre bilinguismo não existe consenso sobre o que caracteriza um indivíduo bilíngue. Conforme Baker (2006) e Romaine (1995), ser bilíngue pode ser caracterizado tanto de forma linguística ou cultural. Como norteador da construção do QueHLAP, está Mackey (1972), que propõe a ideia de não criar um perfil único do que é composto o bilíngue, mas defende que é necessário investigar as diferentes formas de considerar um determinado sujeito bilíngue. Dessa forma, é possível compreender melhor as situações em que a pessoa num determinado momento é bilíngue e em outros não demonstra tal competência bilíngue. 
Nesse sentido de buscar compreender como o bilinguismo transparece no sujeito, podemos, segundo Mackey (1972), utilizar quatro aspectos relacionados a quão bilíngue o indivíduo pode ser, a saber, grau, função, alternâncias e interferências. Cada um desses aspectos será discutido a seguir. (1) Grau: corresponde ao quanto o sujeito conhece da língua, que contempla a produção oral e escrita, e a percepção de leitura e de fala. (2) Função: finalidades de uso e circunstância em que são utilizadas as línguas envolvidas. (3) Alternâncias: a mudança e trocas das línguas que acontecem em determinados momentos e necessidades. (4) Interferências: em que medida existe separação das línguas e quais interferências podem ocorrer. Com esse núcleo de medidas sugeridas, podemos criar critérios uniformes para as discussões do que o QueHLAP pode buscar como respostas, facilitando tanto ao aplicador quanto ao entrevistado uma forma de compreender o que está sendo solicitado.

Romaine (1995) apresenta alguns mitos sobre como é visto o bilinguismo, como o ideal bilingual (bilíngue ideal), full bilingualism (bilinguismo pleno) e o balanced bilingualism (bilinguismo balanceado). Esses conceitos que normatizam que um bilíngue é dessa ou daquela forma, que conhece de forma equilibrada ou na totalidade determinada língua, não se sustenta dentro dos estudos linguísticos bilíngues atuais, pois contemplam as diversas variáveis que envolvem um bilíngue, seja ele precoce ou tardio nas aquisições das línguas adquiridas. Os estudos auxiliam para que o QueHLAP possa fazer uma mensuração geral do bilíngue nas diferentes formas, não focando somente em um tipo de variável, mas abrindo uma opção de possibilidades de bilíngues.

No contexto bilíngue, as pessoas usam diferentes línguas em contextos completamente diferenciados. Vale lembrar um relato de um colega indiano sobre sua situação multilíngue não reconhecida por ele mesmo, uma vez que, ao ser perguntado sobre quantas línguas falava, respondia que falava apenas uma língua. Somente após algum tempo, tomou consciência de que, de fato, falava cinco línguas diferentes. Por que ele não reconhecia inicialmente que falava todas essas línguas? Porque utilizava cada língua em um contexto determinado (uma língua na sala de aula, outra língua em cerimoniais religiosos, outra em casa e assim por diante) e, também, porque ele era um 'falante único'. (QUADROS, 2012, p. 189). 
Esse fator de consciência de compreender que ser bilíngue não precisa ser algo estático, mas sim natural, devemos no ato da pesquisa de autoavaliação, a fim de conseguir extrair dos sujeitos participantes esses subsídios preciosos que pode ser o diferencial, como, por exemplo, a idade de aquisição da(s) língua(s). Com informações diferenciadas, e com bilíngues que possuem uma experiência individual única, temos que ter de forma clara muitos dados que auxiliem na leitura dos testes linguísticos.

A dificuldade de domínio de uso da Libras do professor ouvinte bilíngue bimodal - Libras/Português Brasileiro, pode estar situada nas questões de estruturação da escola bilíngue para surdos e nas escolas inclusivas. A estrutura ofertada é em que o português é colocado com status de língua dos saberes e aprendizagens, e a Libras como uma ferramenta para acessar o português.

... as propostas bilíngues estão estruturadas muito mais no sentido de garantir que o ensino de português mantenha-se como a língua de acesso ao conhecimento. A língua de sinais brasileira parece estar sendo admitida, mas o português mantém-se como língua mais importante dos espaços escolares. Inclusive, percebe-se que o uso "instrumental" da língua de sinais sustenta as políticas públicas de educação de surdos em nome da "inclusão". As evidências das pesquisas em relação ao status das línguas de sinais incomodam as propostas, mas não chegam a serem devidamente consideradas quando da sua elaboração. A língua de sinais, ao ser introduzida dentro dos espaços escolares, passa a ser coadjuvante no processo, enquanto o português mantém-se com o papel principal. As implicações disso no processo de ensinar-aprender caracterizam práticas de exclusão. (QUADROS, 2012, p. 193).

Nosso objetivo é verificar no formato de autoavaliação a proficiência e histórico de linguagem dos professores que ficam nesse espaço escolar com tantas problematizações no campo das políticas linguísticas e educacionais. Dessa forma, podemos oportunizar possibilidades de compreender as necessidades de um docente ouvinte e como qualificar o mesmo, para assim ofertar uma educação adequada para os estudantes surdos.

A formação docente pode sanar alguns problemas comunicativos dentro do espaço escolar, onde o aluno surdo busca sua aprendizagem. Sabendo que o mediador do ensino-aprendizagem é o professor, temos que 
ter consciência não somente que o ambiente escolar é bilíngue bimodal, mas também do histórico político, cultural e social da comunidade surda. $\mathrm{Na}$ atualidade ainda é desejável um professor surdo adulto para servir de modelo linguístico, visto que a família na sua maioria é composta por ouvinte que desconhecem a Libras. E ainda na escola teremos professores na sua maioria ouvinte com baixa fluência ou nenhuma formação formal ou informal em Libras.

A perspectiva da formação formal em Libras em nível de graduação é um dos assuntos abordados em pesquisas atuais na educação de surdos. Desde o surgimento do Decreto Lei 5.626 emergem diversas preocupações e dúvidas sobre qual seria essa formação em Libras através de uma única disciplina obrigatória.

Diversas instituições, na urgência de cumprir prazos estabelecidos pela lei, têm contratado profissionais ou aberto concurso para sanar esse problema. Entretanto, a forma como tal disciplina vem sendo organizada é bastante preocupante, pois não há orientação ou norma que defina os seus objetivos, as necessidades formativas dos alunos ou a carga horária mínima necessária. (SANTOS; CAMPOS, 2013, p. 237).

O Questionário de Histórico de Linguagem e Autoavaliação de Proficiência pode ser um espelho da realidade para orientar nesse processo de construção da disciplina de Libras, mostrando alguns pontos e lacunas que devem ser preenchidas, pois os docentes ouvintes em escolas de surdos podem sinalizar através de suas respostas o que hoje lhes falta em termos de conhecimento da língua de sinais.

A disciplina de Libras nas formações de professores é relativamente recente, contando a data do Decreto Lei 5.626 ser de 2005. Sem ter uma orientação explicita de carga horária, forma e conteúdos mínimos, ela permite que as formações sejam as mais diversas, sendo de 30 horas conforme relata Santos e Campos (2013) ou por nossas experiências de 60 horas nas universidades da região metropolitana de Porto Alegre. Quanto à Libras, por ser uma língua de modalidade diferente do habitual da maioria dos estudantes universitários, muitas pessoas pensam que é muito simples e fácil de aprender. Entre essas crenças, é comum pensar que com uma disciplina de um semestre o indivíduo terá proficiência e poderá comunicar-se com alunos surdos, que poderá usar Libras e Português Brasileiro ao mesmo tempo sobrepondo 
uma língua na outra, esquecendo ou desconhecendo que a Libras possui uma estrutura gramatical própria e independente do Português Brasileiro.

Um fator importante que devemos conceber nessa reflexão que permeia a disciplina de Libras que, para muitos, poderá ser a única formação acadêmica e linguística refere-se aos materiais escassos para o ensino de Libras, como dicionários de aprendizes, mesmo hoje com a internet possibilitando que a circulação de vídeos em Libras e outros materiais circulem. Também é relevante considerar as condições de uma aprendizagem que exige tempo e habilidades linguísticas (SANTOS; CAMPOS, 2013).

O objetivo principal da disciplina, inclusive no texto da lei, é uma melhor formação de professores para atuação em salas de aula inclusivas que, possivelmente, terão a presença de alunos com os mais diversos tipos de deficiência, incluindo a surdez. Infelizmente, o tempo da disciplina não permite o aprofundamento dessas questões, mas a disciplina deve proporcionar ao aluno o conhecimento da Libras que se não usada, esmaecerá -, bem como uma reflexão sobre formas de atuação adequadas para com os alunos surdos, possibilidades de conscientização da diferença linguística e cultural e aceitação da língua portuguesa como segunda língua do aluno surdo. (SANTOS; CAMPOS, 2013, p. 242)

Muito dos futuros professores que são ouvintes e que deveriam ser bilíngues para conseguir a comunicação com seus alunos surdos, durante a graduação não recebem uma formação bilíngue com uma estrutura adequada para formar profissionais habilitados para atuar numa escola de filosofia educacional bilíngue. É importante que a escola proporcione que as discussões ocorram em Libras, que possa haver um crescimento e evolução de discussões na primeira língua (nesse caso Libras), para favorecer que o surdo possa ter subsídios de entendimento de como funciona em sua primeira língua para assim poder estar utilizando na segunda língua. Quadros (2012) discute que o currículo organizado em uma perspectiva visoespacial possibilita acesso dos estudantes surdos em todos os conteúdos escolares. Mas para termos essa organização de ensino em Libras necessitamos ir além de apenas alguns professores surdos, mas de professores ouvintes bilíngues com proficiência em Libras, garantindo estabelecer discussões acerca dos conteúdos previstos nos espaços escolares. 
Assim, a educação de surdos na perspectiva bilíngue toma uma forma que transcende as questões puramente linguísticas. Para além da língua de sinais e do português, esta educação situa-se no contexto de garantia de acesso e permanência na escola. Essa escola está sendo definida pelos próprios movimentos surdos: marca fundamental da consolidação de uma educação de surdos em um país que se entende equivocadamente monolíngue. O confronto se faz necessário para que se constitua uma educação verdadeira: multilíngue e multicultural. Assim, no Brasil, o 'bi' do bilinguismo apresenta outras dimensões. (QUADROS, 2012, p. 198).

A educação de surdos ainda em fase de consolidação, e por questões de políticas linguísticas carece a cada momento de mais pesquisas, e o QueHLAP surge como um auxílio no processo de conhecer determinados grupos de usuários de Libras, salientando que os professores ouvintes bilíngues em diversos casos são os primeiros a terem contato com as crianças ou adolescentes surdos no ingresso escolar, apresentando a Libras e ensinando os primeiros sinais.

\section{Discussões Referentes ao QueHLAP}

Os resultados que podem ser obtidos com aplicações do Questionário de Histórico de Linguagem e Autoavaliação de Proficiência podem se refletir em pistas para elaborar uma construção de um currículo de formação de professores ouvintes bilíngues. A Libras encontra-se no espaço de línguas minoritárias, e nesse momento podemos ver nas discussões de políticas linguísticas através dos movimentos surdos que produzem a cada ano uma nova conquista com novas leis e normativas. Entretanto, nem sempre as práticas estão de acordo com os documentos oficiais.

Para Altenhofem (2013) o termo língua minoritária pode ser aplicado pelo "status social" ou pelo "status político", trazendo essa realidade de enfrentamento nas discussões de educação de surdos. O Português Brasileiro apresenta um grande "rival" tanto para a Comunidade Surda quanto nos processos de formação de professores. O que queremos evidenciar é que por muitas vezes as literaturas contemplam as questões de ensino da língua escrita (Português Brasileiro), mas não colocam o meio de comunicação e interação dos professores ouvintes com seus discentes surdos. 
O QueHLAP, sendo um instrumento de autoavaliação de proficiência unido ao histórico de linguagem, busca compreender também como a filosofia educacional aplicada na escola pode vir a ter impacto na proficiência do professor ouvinte bilíngue. Considerando, conforme Andrade, Aguiar e Madeiro (2009) que a escola pode seguir três filosofias. A (1) oralista, que defende a comunicação através da leitura orofacial, tendo a escrita do Português Brasileiro como apoiador desse processo, não contemplando a Libras. A filosofia da (2) comunicação total, que utiliza uma mistura de línguas, gestualidade com objetivo apenas de comunicar sem a preocupação de qual língua seguir. E a mais desejada pela liderança da Comunidade Surda em nosso país que é o (3) bilinguismo, que apresenta a Libras como primeira língua e o Português Brasileiro na modalidade escrita como segunda língua.

Dependendo da filosofia adotada no meio escolar, os professores terão resultados de proficiência diferentes, ou ainda, mesmo estando na filosofia bilíngue poderão ainda possuir traços da filosofia da comunicação total que era praticada em diversas escolas no Brasil por ter professores ouvintes que não dominavam Libras para o ensino de surdos.

... não é incomum encontrar profissionais que se afirmem adeptos do bilinguismo, apesar de valorizarem e estimularem apenas a oralização sem sequer terem conhecimentos e utilizarem a língua de sinais, o que acreditamos ser fundamental para a evolução linguística e cognitiva do surdo. Na prática, além de priorizarem o aspecto oral da linguagem para a comunicação e a estimulação do desenvolvimento da linguagem da criança, muitas vezes fazem uso de estratégias que caracterizam a comunicação total, como leitura orofacial, uso de gestos próprios da criança e sua família, treinamento auditivo e outros. (ANDRADE; AGUIAR; MADEIRO, 2009, p. 112).

Podemos dizer, neste artigo, que hoje a filosofia da educação bilíngue ainda é nova para as escolas, considerando que diversas escolas deixam de ser denominadas especiais para surdos, para serem escolas bilíngues para surdos recentemente. Campos (2013) apresenta uma discussão sobre as novas políticas educacionais em que a escola muda seus paradigmas e práticas em sala de aula, tendo em vista as questões de direitos dos alunos surdos o uso da Libras como primeira língua. Campos (2013, p. 38) defende, ainda, que "educação inclusiva não significa apenas ofertar o acesso dos alunos às escolas ou à 
língua, é necessária formação profissional específica para se trabalhar com esses alunos [...]". Nessa perspectiva, ter apenas formação, ou somente à língua não possibilita uma educação para esses alunos surdos, teremos que ter profissionais com uma formação acadêmica e linguística que contemple as necessidades de uma escola bilíngue para surdos.

\section{Conclusão}

O QueHLAP para professores ouvintes bilíngues Libras-Português proposto neste artigo é direcionado para professores ouvintes atuantes em escolas bilíngues para surdos e para professores ouvintes do AEE que atuam no ensino de surdos. Essa proposta de questionário evidencia uma gama de possibilidades de perguntas a serem realizadas em contextos em que se necessita avaliar a proficiência de professores ouvintes bilíngues bimodais, sendo que esse questionário pode também ser usado em pesquisas em que se deseja estabelecer relação com resultados obtidos em testes linguísticos de proficiência. Além disso, o QueHLAP é um instrumento que pode ser redimensionado para outros usos, como por exemplo em aplicação em pesquisas com tradutores/intérpretes de Libras, professores de Libras e usuários de Libras, a partir de adaptações pequenas em algumas questões direcionando para qual público que deve ser aplicado. O QueHLAP, nessa versão, é para ser aplicado de forma impressa, mas podendo ser redimensionado em plataforma digital ou ser construído um arquivo digital para aplicação através de equipamentos eletrônicos ou via web.

Para aplicações do QueHLAP em pesquisas futuras, consideramos que seja realizada a validação deste questionário. Como sugestão, aplicações de testes de proficiências independentes para a correlação dos resultados com os apresentados pelos participantes a fim de, dessa forma, verificar se existe correlação com as informações prestadas com a proficiência demonstrada com um teste formal de proficiência.

Julgamos o QueHLAP como um importante instrumento de padronização e organização nas pesquisas bilíngues de professores ouvintes. As pesquisas sobre bilinguismo necessitam levar em consideração qual tipo de bilíngue está sendo avaliado para possuir resultados consistentes, com critérios claros de escolhas de participantes de pesquisas para amostras mais uniformes. 
É essencial conhecer quem são os docentes ouvintes e as trajetórias que traçam até chegarem a uma sala de aula onde a língua de instrução é Libras, tendo o objetivo de planejarmos formação continuada e sólida para esses docentes, principalmente considerando que os cursos de Licenciatura proporcionam uma formação incipiente nas disciplinas de Libras. O Capítulo IV, Artigo $14^{\circ}$ do Decreto-Lei 5626/05 determina que, no caso de crianças e adolescentes surdos, o acesso à educação deve ser através da Libras, mas não estipula diretrizes que guiem a formação dos docentes que atuam nas diversas áreas do saber, assim necessitando de mais pesquisas acerca da proficiência de professores bilíngues nos espaços educacionais direcionados aos estudantes surdos.

Apêndice A - QueHLAP - Questionário de Histórico da Linguagem e Autoavaliação de Proficiência

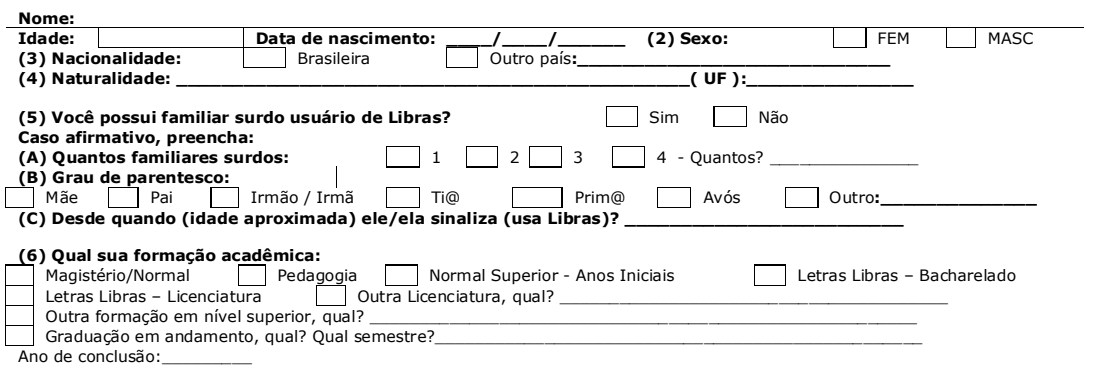

(7) Você possui curso de especialização em:

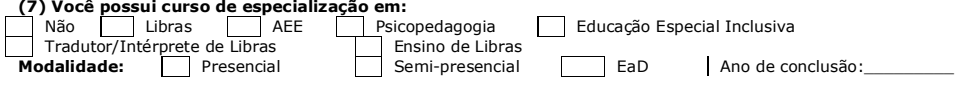

(8) Você possui mestrado em:
\begin{tabular}{|l|l|l|}
\hline Não \\
Outro:
\end{tabular}
Ano de conclusãaçõo:

(9) Você possui curso de Formação de Professores para o Ensino de Surdos (nível de extensão):

\begin{tabular}{ll}
\hline Não & Sim. Carga horária: $\_-\square$ Semi-presencial Onde fez? \\
Modalidade: & $\square$ Presencial \\
\hline
\end{tabular}

(10) Você possui curso de Formação em Atendimento Educacional Especializado (nível de extensão):

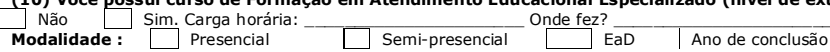

(11) Você possui curso de Tradutor/Intérprete de Libras (nível de extensão):

$\begin{aligned} & \text { (11) Você possui curso de Tradutor/Intérprete de Libras (nivel de exte } \\ & \text { Não } \\ & \text { Modalidade: }\end{aligned}$ Sim. Carga horária: $\quad$ Presencial
M Semi-presencial

Semi-presencial \begin{tabular}{|l|l}
\hline \\
\hline
\end{tabular}

(12) Você possui PROLIBRAS

(12) Voce possui PROLIBRAS
Não Sim de ENSINO - Ano__ Sim de TRADUÇÃO - Ano

(13) Como aprendeu Libras:

\begin{tabular}{|l} 
Em cursos de Libras - Quantos níveis? _ \\
Em disciplina de Libras na graduação - Quantas disciplinas você cursou? \\
Em contato com surdos adultos e participando da Comunidade Surda. Onde:__ \\
Em contato com surdos jovens e participando da Comunidade Surda. Onde: \\
Ao iniciar as atividades de docência na Escola de Surdos. Onde: \\
Aprendi Libras com ( resposta na questão 5 )
\end{tabular} 
(14) Espaço aberto para acrescentar algum comentário que seja pertinente em relação a sua aprendizagem de Libras:

(15) Em caso de usar Português, Libras e ter conhecimento em mais línguas, registre aqui onde e como aprendeu as mesmas:

(16) Meus professores de Libras foram/são:
surdos
$\square$ ouvintes
$\square$ ouvintes e surdos

(17) Liste todas as línguas que você sabe (em ordem de melhor proficiência):

(18) Liste todas as línguas que você conhece e utiliza em ordem de aquisição (sua primeira língua no número um): 1) 2) 4)

(19) ( Libras) Idade que você começou:

Aprender... $\square$ Tornou-se fluente..

(20) Selecione o seu nível de proficiência na fala e compreensão em Libras ( -2 corresponde a nenhum conhecimento, 0 é comunicação mediana e 2 para uma excelente comunicação, no caso de -1 e 1 são os intermediários entre um nível e outro):

Situações

Interagindo com os amigos

Interagindo com a família

Vídeos em Libras

Interação com os alunos

Interação com professores Surdos

\begin{tabular}{|c|c|c|c|c|c|c|c|c|c|}
\hline Fala & \multirow[b]{2}{*}{-1} & \multirow[b]{2}{*}{0} & \multirow[b]{2}{*}{1} & \multirow[b]{2}{*}{2} & \multicolumn{2}{|c|}{ Compreende } & & & \\
\hline $\mid-2$ & & & & & $\mid-2$ & -1 & 0 & 1 & \\
\hline-2 & -1 & 0 & 1 & 2 & -2 & -1 & 0 & 1 & \\
\hline-2 & -1 & 0 & 1 & 2 & -2 & -1 & 0 & 1 & \\
\hline-2 & -1 & 0 & 1 & 2 & -2 & -1 & 0 & 1 & \\
\hline-2 & -1 & 0 & 1 & 2 & -2 & -1 & 0 & 1 & \\
\hline
\end{tabular}

(21) Que línguas você utiliza nessas situações:

Em casa com os pais:

Em casa com irmão ou irmãs:

Com os avós:

Com outros parentes:

Com os amigos:

Com os amigos surdos:

Com os alunos na escola:

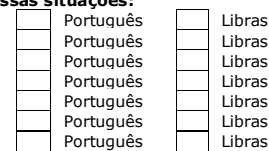

\begin{tabular}{|l|l|l}
\hline & Inglês & Outra: \\
Inglês & Outra: \\
Inglês & Outra: \\
Inglês & Outra: \\
\hline Inglês & Outra: \\
\hline Inglês & Outra: \\
\hline Inglês & Outra: \\
\hline In
\end{tabular}

(22) Você participa de Associação de Surdos?

Não $\square$ Sim. Com que frequência?

(23) Frequência de uso da(s) língua(s) em seu dia-a-dia:

\begin{tabular}{|c|c|c|c|}
\hline Língua & 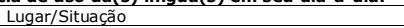 & & Comentários \\
\hline & & $\begin{array}{l}\text { Quantas horas por } \\
\text { dia/Semana }\end{array}$ & $\begin{array}{l}\text { Comentários são bem vindos, para } \\
\text { justificar ou complementar sua resposta. }\end{array}$ \\
\hline \multirow{12}{*}{ Português } & Em casa & & \\
\hline & $\begin{array}{l}\text { Ao visitar membros da família (se não estiver em } \\
\text { casa) }\end{array}$ & & \\
\hline & Na escola & & \\
\hline & $\begin{array}{l}\text { No intervalo escolar com colegas Professores } \\
\text { surdos }\end{array}$ & & \\
\hline & Em reuniões pedagógicas na escola & & \\
\hline & Atividades religiosas & & \\
\hline & Nas brincadeiras e jogos & & \\
\hline & Com os amigos & & \\
\hline & Internet/Youtube & & \\
\hline & Ao fazer refeições & & \\
\hline & Ao rezar & & \\
\hline & Em festas ou eventos sociais & & \\
\hline & & & \\
\hline \multirow{11}{*}{ Libras } & Em casa & & \\
\hline & $\begin{array}{l}\text { Ao visitar membros da família (se não estiver em } \\
\text { casa) }\end{array}$ & & \\
\hline & Na escola & & \\
\hline & $\begin{array}{l}\text { No intervalo escolar com colegas Professores } \\
\text { surdos }\end{array}$ & & \\
\hline & Em reuniões pedagógicas na escola & & \\
\hline & Atividades religiosas & & \\
\hline & Nas brincadeiras e jogos & & \\
\hline & Com os amigos & & \\
\hline & Internet/Youtube & & \\
\hline & Ao fazer refeições & & \\
\hline & Ao rezar & & \\
\hline
\end{tabular}

(24) Na escola em que você atua, as aulas são dadas em:

Português $\square$ Português oral e Libras $\square$ Português escrito e Libras

Português escrito, Escrita de Sinais e Libras

(25) Quando você ensina usando Libras você se sente:

Signum: Estud. Ling., Londrina, n. 17/2, p. 278-301, dez. 2014 
(26) Em suas aulas em Libras, você usa algum recurso para transmitir o conteúdo?

material visual $\square$ escreve no quadro enquanto sinaliza $\square$ Outro:

(27) Quais são as suas maiores dificuldades quanto a usar a Libras no ensino de conteúdos específicos?

(28) Os materiais didáticos com recursos em Libras:

Você cria de forma impressa com suas fotos fazendo sinais

Você cria de forma impressa com fotos dos alunos fazendo sinais.

Você utiliza da internet - Youtube - Sites - Quais por exemplo:

Outros:

(29) Utiliza dicionário de Libras?

Não $\square$ Sim. Quais?

(30) Referente à Escrita de Sinais (SW), marque $X$ nas alternativas correspondentes:

Não sei Escrita de Sinais, nunca fiz nenhum curso e minha escola não utiliza.

Fiz curso de Escrita de Sinais, mas não utilizo, não é da prática da escola.

Fiz curso de Escrita de Sinais, não utilizo, pois somente na disciplina de Libras que é utilizado.

Fiz curso de Escrita de Sinais e utilizo em minhas aulas em $\quad \square$ diversos momentos. $\square$ momentos específicos.

Aprendi Escrita de Sinais na escola de surdos, mas não utilizo em minhas práticas.

Aprendi Escrita de Sinais na escola de surdos e utilizo em minhas aulas em

(31) Sua escola utiliza qual filosofia educacional?
Comunicação Total
Oralismo

Bilinguismo

(32) Assinale com um $X$ sua opinião sobre a Libras e Língua Portuguesa:

\begin{tabular}{|c|c|c|c|c|c|c|c|}
\hline & & Muito & Normal & Não sei responder & Normal & Muito & \\
\hline $\mathrm{a}$ & Bonita & & & & & & Feia \\
\hline b & Fácil de aprender & & & & & & Difícil de aprender \\
\hline $\mathrm{C}$ & Simples & & & & & & Complexa \\
\hline d & Formal & & & & & & Informal \\
\hline e & Útil & & & & & & Inútil \\
\hline$f$ & Boa & & & & & & Ruim \\
\hline$g$ & Agradável & & & & & & Desagradável \\
\hline
\end{tabular}

\begin{tabular}{|l|l|l|l|l|l|l|l|}
\hline \multicolumn{2}{|c|}{ (B) O Português Brasileiro é uma língua ... } & Normal & Muito & \\
\hline & & Muito & Normal & Não sei responder & Noia \\
\hline a & Bonita & & & & & & \\
\hline b & Fácil de aprender & & & & & & Difícil de aprender \\
\hline c & Simples & & & & & & Complexa \\
\hline d & Formal & & & & & & Informal \\
\hline e & Útil & & & & & & Inútil \\
\hline f & Boa & & & & & & Ruim \\
\hline g & Agradável & & & & & & Desagradável \\
\hline
\end{tabular}

(33) Assinale os aspectos gramaticais da Libras que você conhece e ao lado marque o nível de uso ( -2 corresponde a nenhum uso, 0 é uso mediano e 2 para um uso excelente, no caso de -1 e 1 são os intermediários entre um nível e outro):

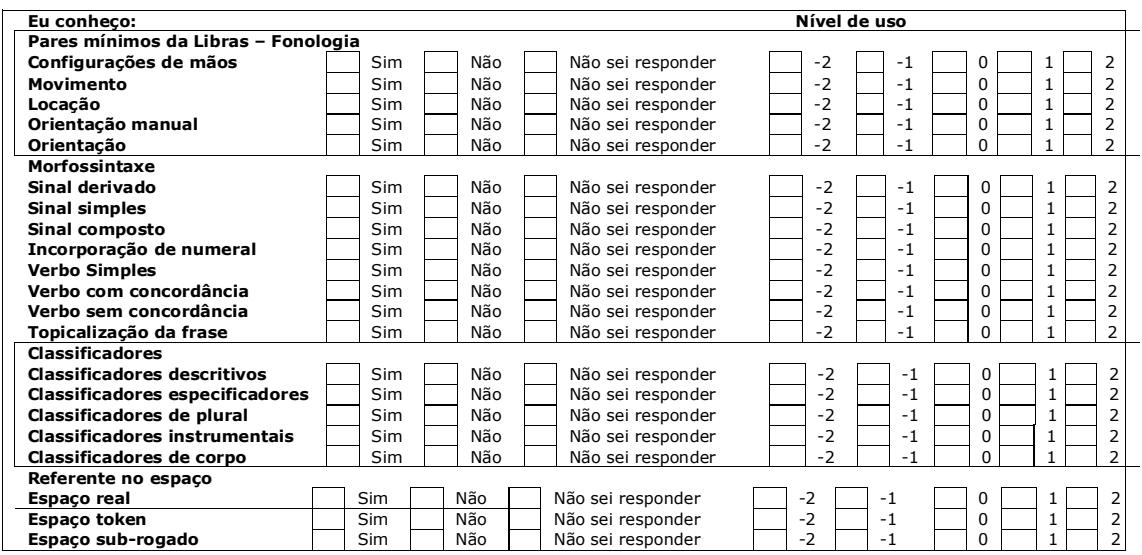

Obrigado por sua participação! 


\section{Referências}

ALTENHOFEN, C. V. Bases para uma política linguística das línguas minoritárias no Brasil. In: NICOLAIDES, C. et al. (Orgs.). Políticas e políticas linguísticas. Campinas: Pontes, 2013. p. 93-116.

ANDRADE, W. T. L; AGUIAR, M. A. M; MADEIRO, F. A surdez na infância: filosofias para a educação da criança surda. In: MATOS, J. C. et al. Linguagem, inclusão e diversidade. Rio de Janeiro: Calibán, 2009. p. 103-120.

BAKER, C. Foundations of bilingual education and bilingualism. 4. ed. Clevedon/Avon: Multilingual Matters, 2006.

BRASIL. Ministério da Educação. Lei no 10.436, de 24 de abril de 2002. Dispõe sobre a Língua Brasileira de Sinais e dá outras providências. Diário Oficial da União, Brasília, DF, 25 abr. 2002. p. 23. Disponível em: <http://goo.gl/EOBpRD>. Acesso em: 17 fev. 2014.

BRASIL. Ministério da Educação. Decreto n ${ }^{\circ}$ 5.626, de 22 de dezembro de 2005. Regulamenta a Lei $n^{\circ}$. 10436, de 24 de abril de 2002, e o artigo 18 da Lei no 10.098, de 19 de dezembro de 2000. Diário Oficial da União, Brasília, DF, 23 dez. 2005. p. 28. Disponível em:

<http://goo.gl/V3KP3E>. Acesso em: 17 fev. 2014.

BRASIL. Ministério da Educação. Portaria no 555/2007, de 07 de janeiro de 2008. Disponível em: <http://goo.gl/liSddu>. Acesso em 20 fev. 2014.

CAMPOS, M. L. I. L. Educação Inclusiva para surdos e as políticas vigentes. In: LACERDA, C. B. F; SANTOS, L. F. Tenho um aluno surdo, e agora? Introdução à Libras e educação de surdos. São Carlos: EDUFSCAR, 2013. p. 37-62.

CHIN, N. B.; WIGGLESWORTH, G. Bilingualism: an advanced resource book. Nova Iorque: Routledge, 2007.

FERREIRA, M. C. C; ZAMPIERI, M. A. Atuação do professor ouvinte na relação com o aluno surdo: relato de experiência nas séries iniciais do ensino fundamental. In: LODI, A. C. B; LACERDA, C. B. F. (Org.) Uma escola, duas línguas: letramento em língua portuguesa e língua de sinais nas etapas iniciais de escolarização. Porto Alegre: Mediação, 2009. p. 99-112. 
FISHMAN, J. Varieties of ethnicity and varieties of language consciousness. In: DIL, A. (Ed.) Language and socio-cultural change: essays by J. Fishman. Standford: Standford University Press, 1972.

GROSJEAN, F. Bilingualism: a short introduction. In: GROSJEAN, F; LI, P. The Psycholinguistics of Bilingualism. Wiley-Blackwell, 2013. p. 5-25.

KAUFMANN, G. Falar espanhol or hablar portugués: attitudes and linguistic behavior on the Brazilian-Uruguayan and Brazilian-Argentinean borders. Romanistisches Jahrbuch, Berlim; New York, v. 60, p. 276-317, 2010.

LODI, A. C. B.; LACERDA, C. B. F. Uma escola, duas línguas: letramento em língua portuguesa e língua de sinais nas etapas iniciais de escolarização. Porto Alegre: Mediação, 2009.

LODI, A. C.; MÉLO, A. D. B.; FERNANDES, E. Letramento, bilinguismo e educação de surdos. Porto Alegre: Mediação, 2012.

MACHADO, V.S.J. Avaliação de proficiência linguística de pilotos: o discurso do candidato e sua influência no comportamento e julgamento do examinador. 2010. Dissertação (Mestrado em Linguística Aplicada) Universidade Federal do Rio de Janeiro, Rio de Janeiro.

MACKEY, W. F. The description of bilingualism. In: FISHMAN, J. A. [Ed.]. Reading in the sociology of language. 3. ed. The Hague: Mouton, 1972. p. 554-584.

MARCONI, M. A.; LAKATOS, E. M. Fundamentos de metodologia cientifica. 7. ed. São Paulo: Atlas, 2010.

MARIAN, V., BLUMENFELD, H. K.; KAUSHANSKAYA, M. The Language Experience and Proficiency Questionnaire (LEAP-Q): assessing language profiles in bilinguals and multilinguals. Journal of Speech, Language, and Hearing Research, v. 50, n. 4, p. 940-967, Aug. 2007.

OLIVEIRA, G. M. (Org.). Declaração Universal dos Direitos Lingüísticos: novas perspectivas em política lingüística. Campinas: Mercado de Letras/ALB; Florianópolis: IPOL, 2003.

PEREIRA, M. C. C. Papel da língua de sinais na aquisição da escrita por estudantes surdos. In: LODI, A. C.; MÉLO, A. D. B.; FERNANDES, E. 
(Orgs.). Letramento, bilinguismo e educação de surdos. Porto Alegre: Mediação, 2012. p. 235-246.

QUADROS, R. M. O “bi” em bilinguismo na educação de surdos. In: LODI, A. C.; MÉLO, A. D. B.; FERNANDES, E. (Orgs.). Letramento, bilinguismo e educação de surdos. Porto Alegre: Mediação, 2012. p. 187-200.

REEVES, J. B.; NEWELL, W.; HOLCOMB, B. R.; STINSON, M. The Sign Language Skills classroom observation: a process for describing sign language proficiency in classroom settings. American Annals of the Deaf, v. 145, n. 4, p. 315-341, Oct. 2000.

ROMAINE, S. Bilingualism. 2. ed. Oxford: Basil Blackwell, 1995 [1989]. (Language in society; 13.).

SANTOS, K. R. O. R. P. Projetos educacionais para alunos surdos. In: LODI, A. C.; MÉLO, A. D. B.; FERNANDES, E. (Orgs.). Letramento, bilinguismo e educação de surdos. Porto Alegre: Mediação, 2012. p. 71-88.

SANTOS, L. F; CAMPOS, M. L. I. L. O ensino de Libras para futuros professores da Educação Básica. In: LACERDA, C. B. F; SANTOS, L. F. (Orgs.) Tenho um aluno surdo, e agora? Introdução à LIBRAS e educação de surdos. São Carlos: Editora EdUFSCar, 2013. p. 237-250.

SKLIAR, C. Atualidade da educação bilíngue para surdos: interfaces entre pedagogia e lingüística. Porto Alegre: Mediação, 1999.

Recebido em: 10/01/2014 Aceito: 18/02/2014 